\title{
EQUAL PROPORTION REPRODUCTION METHOD OF GROTTO BASED ON POINT CLOUD
}

\author{
Putong Wei ${ }^{1,2}$, Aiqun $\mathrm{Li}^{1}$, Miaole Hou ${ }^{1,2, *}$, Lei Zhu ${ }^{1}$, Donghui $\mathrm{Xu}^{1}$, Bo Ning ${ }^{3}$ \\ ${ }^{1}$ Beijing University of Civil Engineering and Architecture, No.15Yongyuan Road, Daxing District, Beijing, 102616,China - \\ 210813J117014@stu.bucea.edu.cn, liaiqun@bucea.edu.cn, houmiaole@bucea.edu.cn, zhulei@bucea.edu.cn, \\ xudonghui@bucea.edu.cn \\ ${ }^{2}$ Beijing Key Laboratory For Architectural Heritage Fine Reconstruction \& Health Monitoring, No.15Yongyuan Road, Daxing \\ District, Beijing, 102616,China \\ ${ }^{3}$ Yungang Grottoes Research Institute, Datong, 037007, China -ningbo007@163.com
}

Commission II, WG II/8

KEY WORDS: Cultural relics reproduction, 3D laser scanning, Point cloud, 3D printing

\begin{abstract}
:
The rapid development of 3D laser scanning and 3D printing technology provides new technologies and ideas for cultural relic protection and reproduction. Aiming at the requirement of equal proportional reproduction of large-scale grottoes, this paper takes the point cloud data of the 18th Cave of Yungang Grottoes obtained by 3D laser scanning as an example, and proposes a data processing and reproduction block partitioning method for equal proportion reproduction. The Cyclone, Geomagic and AutoCAD software were used to construct the 3D model of the grotto, and the 3D printing technology was used to realize the secondary design and model print. Among them, the research focuses on the modeling of massive point clouds and the method of model partitioning based on voxels. It can meet the requirements of movable and assembly while realizing the equal proportional reproduction of the whole grotto. The research results and application can be a good reference for the future grotto reproduction work.
\end{abstract}

\section{INTRODUCTION}

The grottoes are the crystallization of wisdom left by the ancestors, an important testimony of human civilization, and have great artistic value, research value and ornamental value. However, most of these cultural relics are immovable and can only be displayed at the location of the cultural relics, which undoubtedly limits their dissemination ability and related research. Therefore, it is of great practical significance and application value to study the method of grottoes reproduction. At present, applying new technologies to reproduce cultural relics in equal proportions for inheriting and displaying grotto culture better without damage to cultural relics has become a global issue. With the development of 3D acquisition and manufacture related technologies, 3D information retention has become the basic work of cultural relics reproduction. The accurate 3D data provides the support for high-fidelity and highresolution reproduction of large-scale grottoes; The digital reproduction technology based on $3 \mathrm{D}$ printing has replaced the traditional mold-making technology and becomes the commonly used technical means of cultural relics reproduction.

In 2004, DIAPREM and CNR-ISTI's project team used 3D printing technology to complete the reproduction in 1:1 scale of parts of the Pompeii wall. The large model $(270 \times 330 \mathrm{~cm})$ was divided into 125 tiles, All these pieces were mounted correctly using a supporting structure, This method can only copy planar cultural relics (Balzani et al., 2014). Alemanno et al. decomposed the 3D model into a set of easy-to-manufacture and assembly components, and 3D printed a scaled down reproduction of the Ruthwell Cross, an Anglo-Saxon tall stone cross, which has a low joint strength and is not suitable for replication of large scale cultural relics (Cignoni et al., 2014). In 2013, Shanghai Printing Co., Ltd. used 3D laser scanning and 3D printing technology to complete the equal proportion reproduction of the 80-squaremeter Xinjiang Kuzi Cave. The reduction degree of the reproduction was $98 \%$, but the disassembly and transportation of the replica was not convenient (Yang, 2017). In 2017, Italian scholars F. Di Paola, G. Milazzo b, and F. Spatafora used 3D printing technology to copy and repair the broken leg parts of the Zeus God sculpture. The project is mainly based on small volume missing areas for 3D reconstruction and printing (Milazzo et al., 2017). However, in general, most of reproduction work for cultural relics focus on the level of movable small objects. The research on equal proportional reproduction of large-scale immovable Grottoes is currently in its infancy, and there are still many drawbacks.

This study takes the 18th Cave of Yungang Grottoes as an example to discuss the reproduction process and data processing method of large-scale grottoes.Combining the advantages of Cyclone, AutoCAD and Geomagic platforms, the 3D model reconstruction and processing of the 18th Cave of Yungang Grottoes was carried out, and the digital model was designed and 3D printed, and finally displayed in kind. The innovation of this paper is to use 3D laser scanning technology to obtain the geometric information of the grotto accurately and quickly through non-contact and non-destructive methods. Combining with the value of grotto surface to construct the TIN model and the contour map and section map to provide an important data basis for Grottoes replication. And a 3D printed grotto reproduction method is proposed to materialize the huge grotto model, which provides a reference for the high fidelity reproduction of the grotto cultural relics, and is of great significance for strengthening the protection of grotto and the diversified application of surveying results.

\footnotetext{
* Corresponding author
} 


\section{POINT CLOUD 3D RECONSTRUCTION}

The 3D reconstruction of the model of this project requires three stages: point cloud acquisition, point cloud processing, and 3D reconstruction. The flow chart is shown in Figure 1.

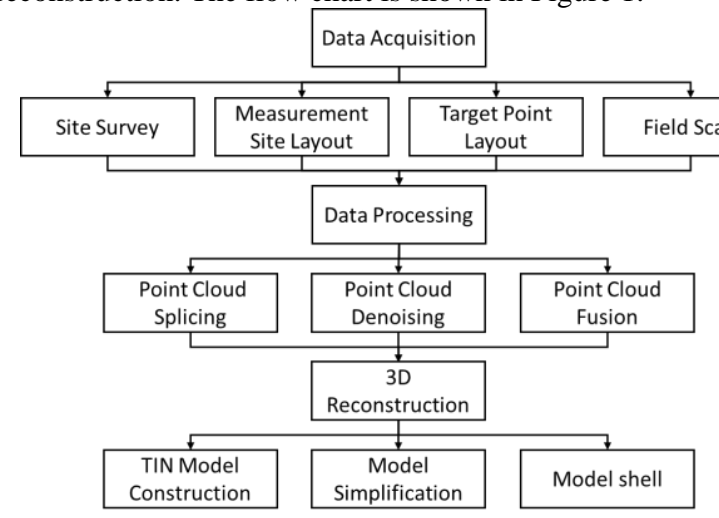

Figure 1. The process of point cloud acquisition and threedimensional reconstruction

\subsection{Data Acquisition}

Through on-site survey and inspection of relevant information, it shows that The 18th Cave is one of the earliest "TanYao Five Caves" excavated in Yungang Grottoes, The statue is magnificent The plane of the cave is an elliptical plane. The whole cave is horseshoe-shaped with a dome.and gradually shrinks from bottom to top. The height of the grotto is nearly 17 meters, the width is 17.5 meters, and the length is 8 meters. The height of the main statue of the north wall is $15.5 \mathrm{~m}$. On both sides of the east and west, there are other Buddha statues. The south wall is mainly carved by thousands of Small Buddha statues, and the size and fineness of the statues are different (Wu, 2015), as shown in Figure 2.

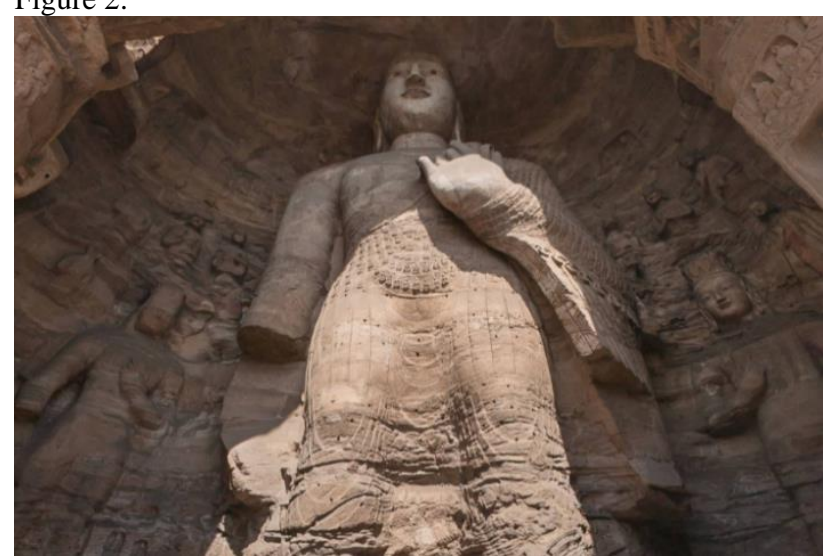

Figure 2. The 18th Cave of Yungang Grottoes

Taking into account the size and precision of the grotto, combined with the surrounding environment of the grotto. In this paper, multi-station high-precision scanning of grottoes is carried out by using different 3D laser scanners with different performance, Scaffolding is used to assist data collection to minimize data loss. Before the scan, scaffold is set up on the ground according to the environmental conditions of the grotto before scanning, layer by layer. There are at least three registration target balls between adjacent stations for data registration. The distance from the station to the Grottoes is 5-50 M. Riegl VZ-400 (point accuracy: $5 \mathrm{~mm} / 100 \mathrm{~m}$ ) is used to collect the whole grotto data (including the inner and outer areas). At the same time, the ArtecSpider 3D scanner with an accuracy of $0.03 \mathrm{~mm}$ was used for scanning details and dead angle. Draw a sketch of the scanning station of the survey area, record the location of the scanning station, the operator, the scanning mode, etc., so as to facilitate the data processing and the retention of the on-site data.

\subsection{Point Cloud Data Processing}

3D data processing is the key and foundation for subsequent results production. Since the object is obtained by multi-station scanning, the point cloud data of each station has an independent coordinate system based on the scanner.In the point cloud data of any station, the relative positional relationship between the scanning points is correct, and the relative positional relationship of the points cloud between different stations depends on whether they are in the same coordinate system. In order to obtain the complete 18th Cave scan result, the point cloud obtained by multiple stations needs to be spliced and registered to the same coordinate system, that is, the point $(\mathrm{x}, \mathrm{y}, \mathrm{z})$ in a coordinate system of a station. After the rigid body transforms to the target coordinate system $(\mathrm{X}, \mathrm{Y}, \mathrm{Z})$, as shown in formula 1 :

$$
\left[\begin{array}{l}
X \\
Y \\
Z
\end{array}\right]=R\left[\begin{array}{l}
x \\
y \\
Z
\end{array}\right]+T
$$

where $\quad$ R: Third-order rotation matrix $\mathrm{T}$ : Translation matrix

Then, based on the spherical target splicing method, the Spherical equation is fitted by the scanned target point cloud, and the spherical center coordinates are used as the target point for splicing. Select more than three targets of the same name to register the point cloud data to achieve the overall splicing, so that the overall point cloud data splicing error after splicing is no more than $3 \mathrm{~mm}$ (Sheng et al., 2014). Taking one of the splicing as an example, the error of splicing is shown in Table 1, and the data of point cloud of 18th Cave after splicing is shown in Figure 3.

\begin{tabular}{|cccccc|}
\hline $\begin{array}{c}\text { Splicing } \\
\text { Method }\end{array}$ & \multicolumn{5}{c|}{ Spherical Target } \\
\hline $\begin{array}{c}\text { Target } \\
\text { Number }\end{array}$ & A25 & A26 & A27 & A29 & A31 \\
Error (m) & 0.001 & 0.001 & 0.001 & 0.002 & 0.001 \\
\hline
\end{tabular}

Table 1. Target splicing error
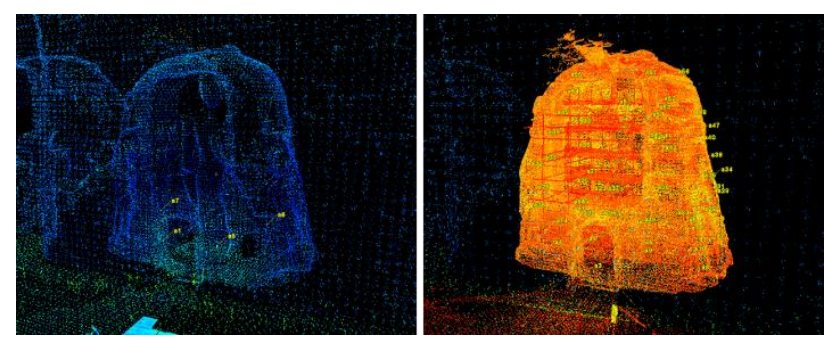

Figure 3. Point cloud data before and after splicing

Due to many conditions during the scanning process, the original point cloud data inevitably contains noise points, such as nontarget points, isolated points, and the like. These noises not only affect the amount of data and modeling speed, but also reduce the quality of the $3 \mathrm{D}$ model.In this paper, the noise reduction processing is performed by means of filtering and humancomputer interaction. The point cloud effect after denoising is shown in Figure 4. According to the requirements of subsequent production results, data fusion is performed by adjusting the sampling rate parameters and selecting an appropriate average sampling interval. 


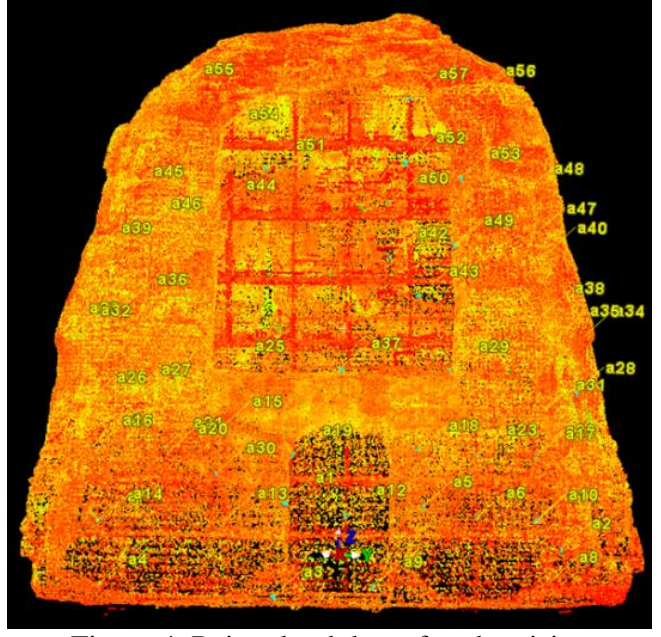

Figure 4. Point cloud data after denoising

\subsection{D Reconstruction}

After the fusion, the number of point clouds is as high as 400 million. These point clouds are composed of irregular spatial discrete points, In order to get the real surface of cultural relics with topological relationship, it is necessary to construct highprecision irregular triangular network model (TIN model) through point cloud.

This paper uses Geomagic Studio platform to reconstruct point clouds in three-dimensional. In order to improve the modeling efficiency, the TIN model is constructed by using the block-byblock modeling method to separate the multiple faces of the 18th Cave and merge them according to the coordinate system. Then according to the artistic value of the Grotto surface, the Buddha statue and the space environment in the caves are classified, and the model is simplified according to the classification result, further reducing the amount of data. The model data and photos are comprehensively analyzed, and the Buddha statues and space environment are classified by engraving method and content.The most important contents are the Buddha, Bodhisattva and Luohan Statue. Most of these parts are alto-relievo, which are the key value areas and are classified into Class I; A large number of reliefs as a basic Buddhist grotto background environment belong to Class II; Classes that do not contain historical information such as weathered sandstone bodies and uncarved mountains are classified as Class III.At the same time, Class I is divided into two categories according to the fine grade, $\mathrm{A}$ and $\mathrm{B}$. The $\mathrm{A}$ is a partial fine content, such as a Crown, Gown, Ornament. Class B is the majority of the high relief parts of the Buddha statue. The specific classification is shown in Table 2. After simplification, the number of triangular faces of the TIN model is controlled at about 80 million.

\begin{tabular}{|cccc|}
\hline Content & $\begin{array}{c}\text { Art value } \\
\text { classification }\end{array}$ & $\begin{array}{c}\text { Area } \\
\left(\mathrm{m}^{2}\right)\end{array}$ & $\begin{array}{c}\text { Simplification } \\
\text { rate }\end{array}$ \\
\hline $\begin{array}{c}\text { Crown, Gown, } \\
\text { Ornament } \\
\text { Buddha, }\end{array}$ & Class I A & 54 & $50 \%$ \\
$\begin{array}{c}\text { Bodhisattva and } \\
\text { Luohan Statue } \\
\text { Buddhist Grotto } \\
\text { Background } \\
\text { Relief }\end{array}$ & Class I B & 276 & $40 \%$ \\
$\begin{array}{c}\text { Weathered } \\
\text { Sandstone, } \\
\text { Uncarved Rock }\end{array}$ & Class II & 242 & $30 \%$ \\
\hline
\end{tabular}

Table 2 Surface art value classification statistical table
In order to effectively connect with digital manufacturing technology. Finally, the whole model was subjected to shelling treatment, and the thickness of the shell was $4 \mathrm{~cm}$, which realized the transformation of the model from face to body. After the model mesh optimization and the hole filling, the threedimensional reconstruction of the18th Cave is completed as shown in Figure 5.

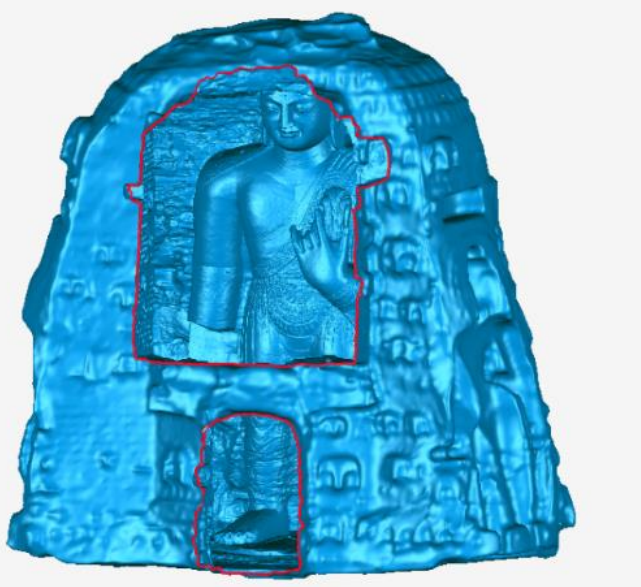

Figure 5. Three-dimensional model of the surface of the 18th Cave of Yungang Grottoes

\section{REPRODUCTION BLOCK PARTITIONING}

The three-dimensional model is finally manufactured in a physical way. However, due to the limitations of the current technology, it is impossible to print the grotto as a whole. It is necessary to divide the huge grotto surface model into a number of sub-models according to certain rules and print them separately. These sub-models ultimately rely on steel structures as a support to form a complete grotto surface model. Therefore, this paper adopts a voxel-based model partitioning scheme to ensure the success of reproduction.

Firstly, the necessary attitude adjustment and coordinate system setting are performed on the model, and the Cartesian coordinate system is established as shown in Figure 6. Considering the actual production and transportation capabilities, choose 2 meters as the step size to perform voxel segmentation on the model. The 18th Cave surface model is divided into 288 square voxel spaces with a length of 2 meters. Traverse all voxel spaces, if the model exists in the voxel, it is 1 , and if there is no model, the voxel is 0 . All voxels with a value of 1 are voxel models, as shown in Figure 7.

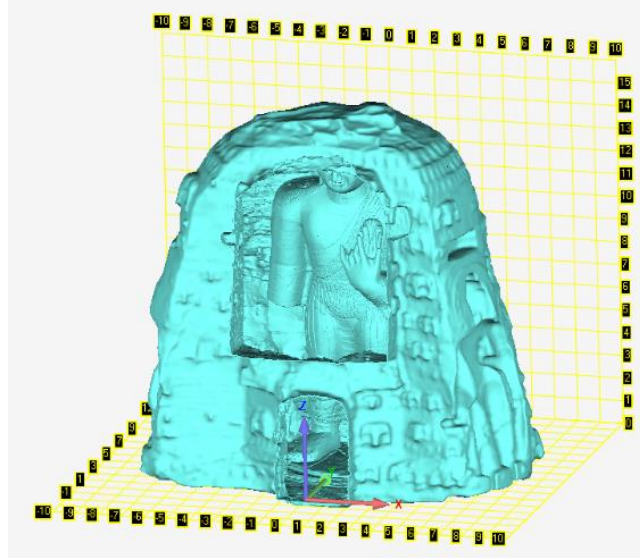


Figure 6. Establishing a Cartesian coordinate system at the center of the entrance

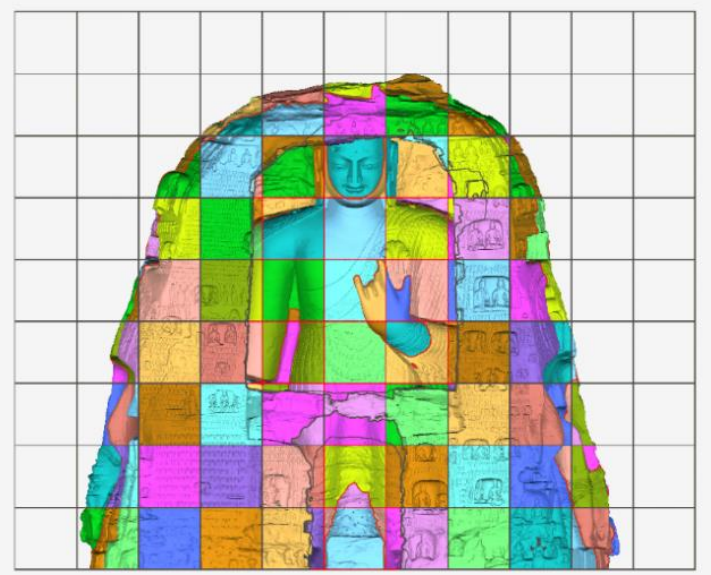

Figure 7. Voxelization model

In this paper, the partial area of the 18th Cave is used as the reproduction area. Obviously, too many voxeln models bring many inconveniences to data management, digital manufacturing and later installation. Considering that the cantilever direction of each voxel model connected to the steel structure during construction will be unique (X direction or Y direction), and the voxel model in the same direction will be combined to obtain sub-models, as shown in Figure 8, there are a total of 70 submodels.

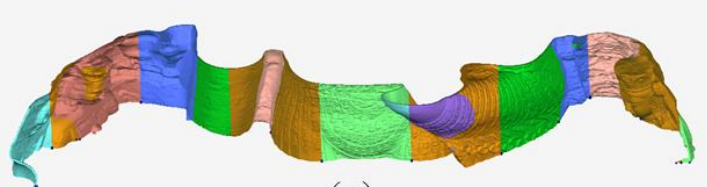

(a)

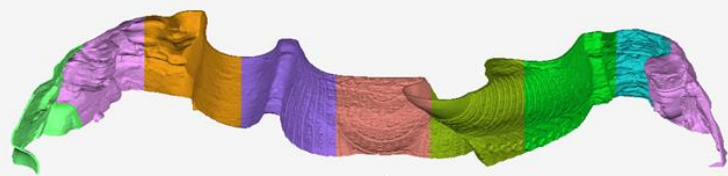

(b)

Figure 8. (a) The original voxelization model with the fourth layer as an example

(b) Merged fourth layer sub-models

After the partition is completed, the simulation of the scheme is carried out, as shown in Figure 9, and the drawing is drawn by AutoCAD, as shown in Figure 10.

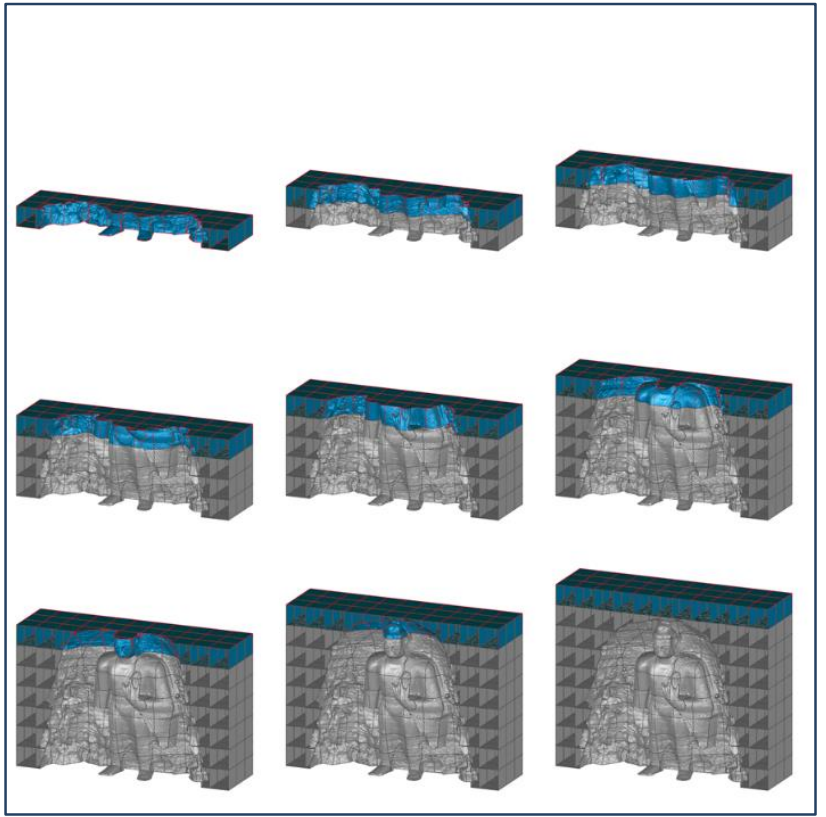

Figure 9. Reproduction method simulation

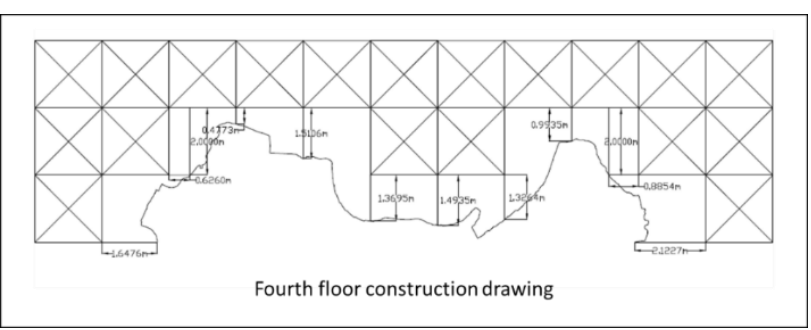

Figure 10. CAD construction drawings

\section{PRINTING AND INSTALLATION}

Common 3D printing technologies include Fused Deposition Modelling (FDM), Selective Laser Melting (SLM), Stereo Lithography Appearance (SLA), Laminated Object Manufacturing (LOM), etc (Liu et al., 2015). The 3D printer used in this paper uses the FDM approach. In FDM devices, a thin filament of plastic is melted in a extruding head and deposited to build the desired shape slice by slice on a moving platform. This approach only requires fairly simple mechanics (very similar to the printing head of a $2 \mathrm{D}$ printer). Therefore, this class of devices is the cheapest on the market (Scopigno et al., 2015). This project takes polylactic acid (PLA) as raw material, convert the submodels into the STL format and import it into the printing software. Set the printing parameters, load the PLA material, and start printing. The resulting 3D printing model is shown in Figure

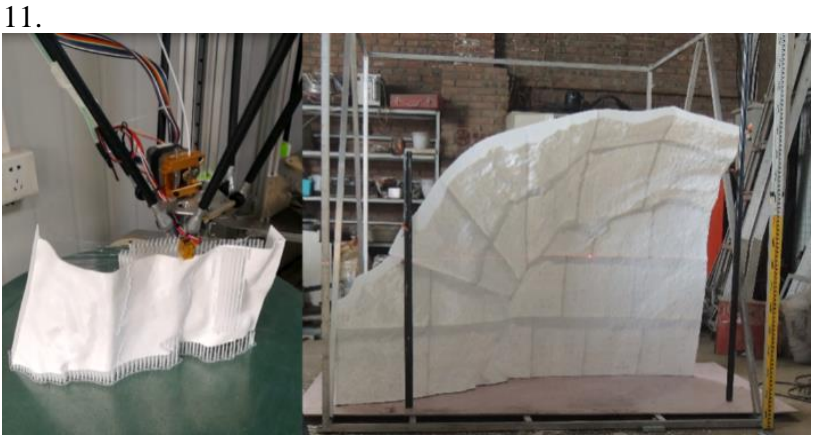

Figure 11.3D printed sub-models 
The printed sub-models are combined into a complete grotto reproduction through the support structure. In this paper, a building block assembly structure is used as the support structure type. The structure is composed of a single square steel frame (module) with a fixed side length of 2 meters, a weight of about 65 kilograms and connected by bolts, as shown in Figure 12. After the sub-model and the supporting structure module are connected by cantilever, they are combined together in a way as building blocks. The 20-day assembly achieve equal proportion reproduction of the whole grotto, and the final reproduction is 18 meters high, 22 meters long, 6 meters wide and weighs about 40 tons, as shown in Figure 13.

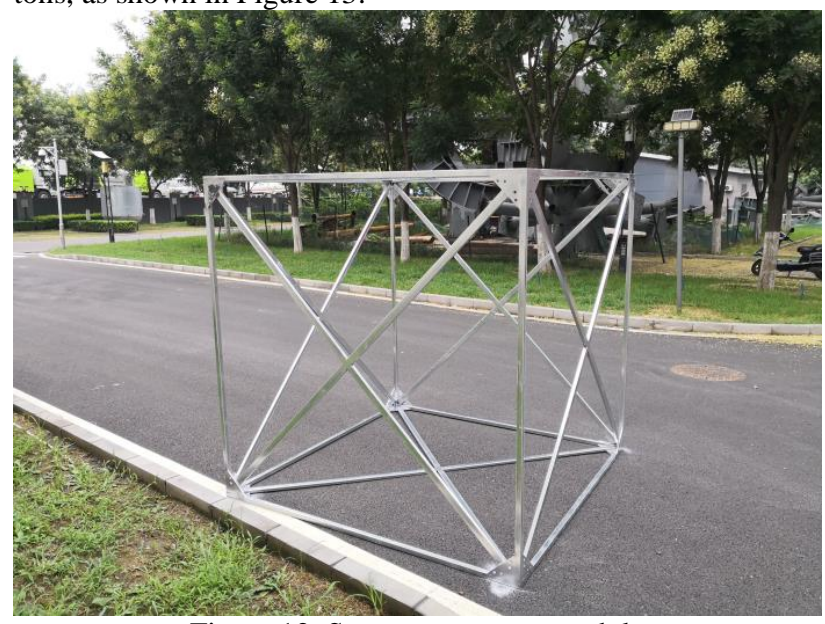

Figure 12. Support structure module

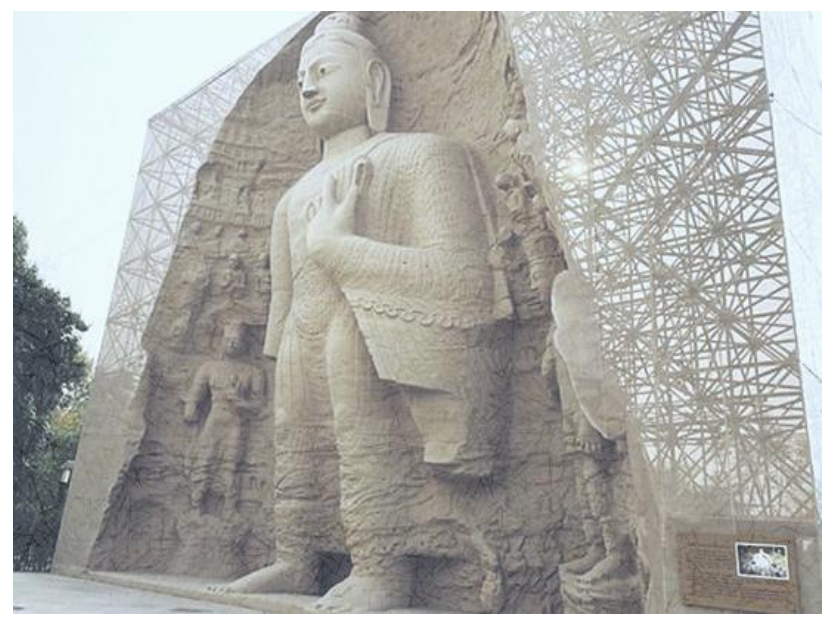

Figure 13. Reproduction of the The 18th Cave of Yungang Grottoes

\section{CONCLUSION}

In this study, the massive point cloud obtained by 3D laser scanning is used as the data source. Through the practice, a method of reproduction large-scale cultural relics is explored, and the equal proportion and high fidelity reproduction of The 18th Cave of Yungang Grottoes is realized. Reproduction can be displayed instead of original objects, so that more people can appreciate these great works of art at close range. From threedimensional reconstruction to final printing, the feasibility and applicability of these techniques in the reproduction of grottoes are illustrated, which opens up a new way for the reproduction and research of similar large-scale cultural relics in the future.

\section{REFERENCES}

Balzani, M., Callieri, M., Fabbri, M., Fasano, A., Montani, C., Pingi, P., et al., 2004. Digital representation and multimodal presentation of archeological graffiti at pompei. In: Vast International Symposium on Virtual Reality Archaeology \& Cultural Heritage, Vol. 4, pp. 93-103.

Cignoni, P., Pietroni, N., Ponchio, F., Scopigno, R., 2014. Interlocking pieces for printing tangible cultural heritage replicas. In: Eurographics Workshop on Graphics \& Cultural Heritage, Eurographics Association, pp. 145-154.

Yang, Y. P., 2017. The original proportion 3D reproduction project of The 3rd Cave of Yungang Grottoes landed in Qingdao. In: China National Cultural Heritage Administration website,

http://www.sach.gov.cn/art/2017/12/18/art_722_145902.html(1 February 2019)

Milazzo, G., Spatafora, F., 2017. Computer aided restoration tools to assist the conservation of an ancient sculpture. the Colossal Statue of Zeus Enthroned. ISPRS - International Archives of the Photogrammetry, Remote Sensing and Spatial Information Sciences, XLII-2/W5, pp. 177-184.

Scopigno, R., Cignoni, P., Pietroni, N., Callieri, M., Dellepiane, M., 2015. Digital fabrication techniques for cultural heritage: a survey. Computer Graphics Forum, Vol. 36, No. 1, pp. 6-21.

Liu, L. G., Xu, W. P., Wang, W. M., Yang, Z. W., Liu, X. P., 2015. Survey on geometric computing in 3D printing. Chinese Journal of Computers, 37(10), pp. 1-28.

Sheng, Y. H., Zhang, K., Zhang, K., Wang, Y. B., 2010. Seamless muti station merging of terrestrial laser scanned 3D point clouds. Journal of China University of Mining \& Technology, 39(2), pp. 233-237.

Wu, Y. Q., 2015. The application of digital technology in Yungang grottoes eighteen cave. Urban Geotechnical, Investigation \& Surveying. 